\title{
Endometriosis encountered in a primigravida and a primipara at caesarean section: Report of two cases.
}

\author{
Neeva Ojha, Akinchan Kafle, Poonam Koirala, Isha Shrestha, \\ Savana Sharma, Sapana Amatya, Seeta Ghimire, Ashma Rana, Geeta Gurung. \\ TU Teaching Hospital, Kathmandu Nepal.
}

\begin{abstract}
Two cases of posterior uterine surface endometriosis were found at caesarean section in primigarvida and primipara consecutively. These cases are reported to convey the importance of Depo-Provera (depot medroxy progesterone), a three monthly injectable progesterone during the immediate post partum period to avoid the complication that may arise from the surrounding endometriotic deposits during the puerperium and afterwards.
\end{abstract}

Keywords: endometriosis coexiting with pregnancy, Depo-Provera.

\section{Introduction}

Spontaneous pregnancy and endometriosis is rare happening, so there are only few reported cases. ${ }^{1}$ Treatment of external endometriosis has resulted in term vaginal delivery with untoward complication of uterine rupture in the presence of adenomyosis. ${ }^{2}$ In addition, postpartum detection of adenocarcinoma in the muscular layer, close to the uterine serosa has been mentioned, that was presumed to derive from adenomyosis coexisting with pregnancy. ${ }^{3}$ Besides these, massive hemoperitoneum have been combated during pregnancy or puerperium. ${ }^{4,5}$

Pregnancy and coexistent endometriosis are recognized to cause complications during pregnancy and puerperium. A decidualized endometrioma has been mistaken for ovarian malignancy or perineal endometrioma has been an additional problem during pregnancy. ${ }^{6,7}$ While colonic perforation has arisen during postpartum period. ${ }^{8}$

However, two cases of endometriosis in posterior surface of uterus, detected at caesarean section in asymptomatic women, with no problem conceiving or any other symptoms related to endometriosis are described here.

\section{Case I}

Twenty seven years, primigravida, who conceived within two months of planned pregnancy, received regular antenatal checkups in our hospital. Her antenatal period was uneventful except that there was no spontaneous onset of labor even at 41 weeks of pregnancy. In view of postdated pregnancy and poor Bishop's Score $(<4)$, induction was done with two doses of dinoprostone gel 500mg, 6 hours apart. The progress of labor was monitored but an emergency caesarean was decided for persistent fetal tachycardia (FHR 170-200 bpm) and non progress of labor at cervical dilatation of $3 \mathrm{cms}$. At caesarean an alive baby girl, $3500 \mathrm{gms}$ weight was delivered with good Apgar score. There were raw congested areas, yellowish green deposits here and there amidst multiple match stick burn like deposits studded over posterior surface of the uterus covering the entire anatomy. Uterine and abdominal closure was done. She had uneventful post operative period and was discharged on day $3^{\text {rd }}$ post operative day. 


\section{Case 2}

Thirty six years $\mathrm{G}_{5} \mathrm{P}_{1+3}$ had supervised pregnancy in our hospital with uneventful antenatal period. However her obstetric history was significant. She was married for 10 years. The first pregnancy happened one year after marriage, which spontaneously ended in early abortion at 6-8 weeks of gestation. In the second pregnancy 9 years back, she ran a post dated course and the labor was induced but failed to progress. So, an emergency caesarean section was done and healthy baby was delivered with uneventful intraoperative or post operative period. There were two consecutive spontaneous abortions at 11/2-3 months gestation, 6 and 5 years back. She had not been using any forms of contraception for the last 5 years. Then this index pregnancy happened and antenatal period was normal. At $36^{+5}$ weeks of gestational age, she presented with lower abdominal pain when scar tenderness was noted on abdominal examination. For this, she was taken for emergency caesarean section. Intraoperatively, dense adhesions were encountered between rectus sheath, muscle layer, peritoneum and the anterior uterine wall. The bladder was displaced high up. With difficulty, an alive baby weighing $2650 \mathrm{gms}$ was delivered from the intact lower uterine segment. Placental delivery was followed by exteriorization of the uterus. Thereby, the repair of uterine incision was completed. During exploration, dark brown endometrioses patches were found to be entirely casing the posterior surface of uterus with smaller gaps with scattered extension to tubes, ovaries and pouch of Douglas (fig 1. schematic diagram). Her immediate post operative period was uneventful. She was discharged on $3^{\text {rd }}$ postoperative day with an advice to take depot medroxy progesterone acetate 3 monthly injections regularly for 2-3 years period.

Retrospectively, history did not reveal any past history of dysmenorrhoea, premenstrual spotting, chronic pelvic pain, dyspareunia, dyschezia, dysuria, hematuria, hemoptysis, chest pain or altered bowel habits in both cases 1 and 2 .

\section{Comment}

The cases concern the description of characteristics of endometriosis, one with diffuse endometriotic deposits studded all over the posterior uterine surface. The other, having greenish brown paste extensively painted over the posterior uterine surface in form of loose plaster.

Endometriosis is usually associated with infertility and both cases were unusual as they had effortless conception at the desired time. This may be due to the involvement of posterior uterine surface and not the ovary or the fallopian tubes. External endometriosis in such situation has been closely associated with fixed uterine retroflexion and incarceration during pregnancy. ${ }^{9}$ Other risk noted were pregnancy failure. ${ }^{10}$

The last is the common complication associated with endometriosis. Overall, scar endometriois, endometriosis of the abdomen wall or those involving rectus muscles are seen more frequently after caesarean delivery. This fact can be addressed by the findings of $126(3.7 \%) / 3384$ multiparous women who underwent laparoscopic tubal sterilization that were detected to have endometriosis. ${ }^{11}$

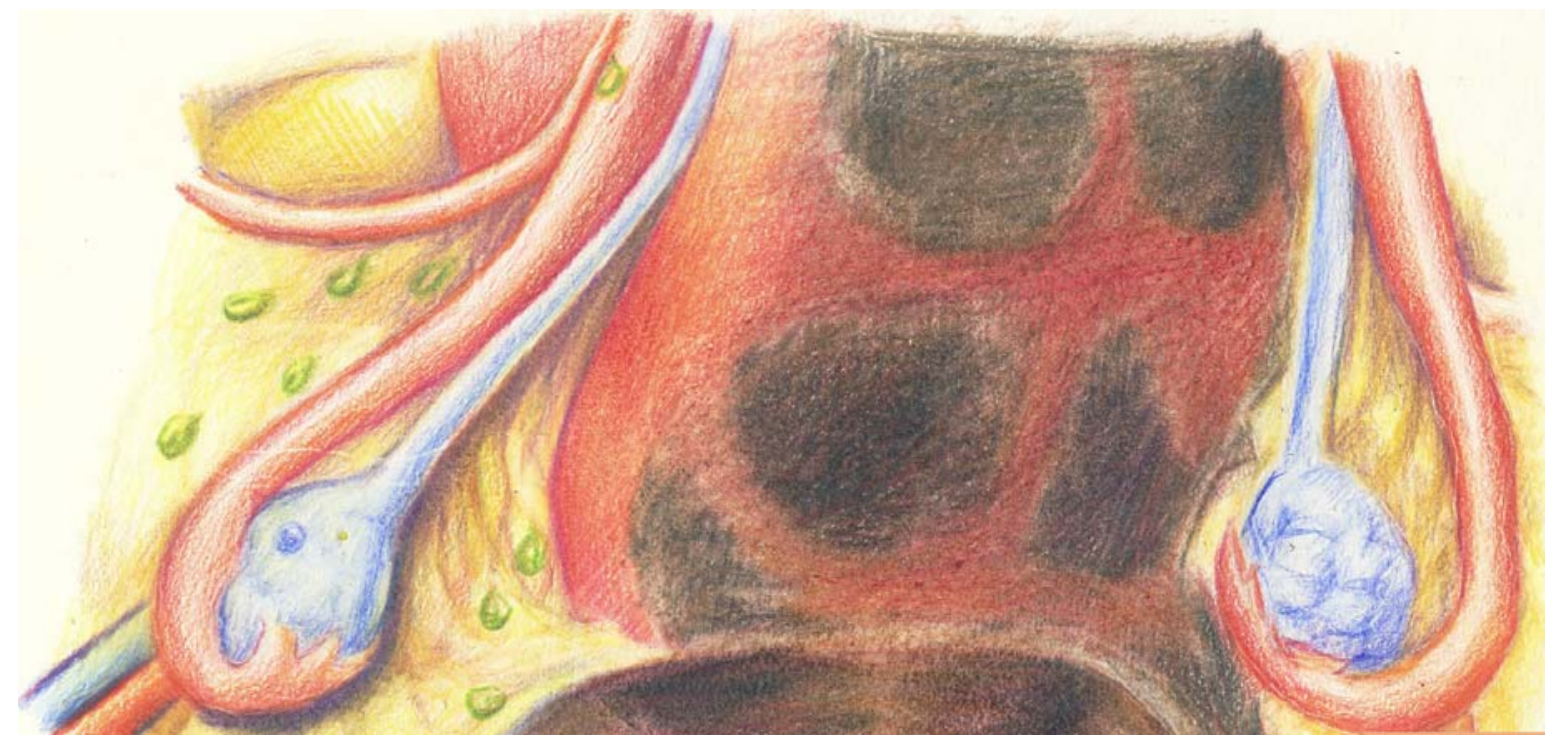

Fig I. Endometriosis seen during caesarean section (courtesy: Dr. Akinchan Kafle) 
Biopsies taken at laparoscopy from suspected peritoneal endometriotic implants in asymptomatic women, with previous at least one caesarean section, have also shown predominating epithelial or stromal components. Perl's method have evidenced, ferric iron, from these foci, that correlated long-standing haemorrhagic lesions. ${ }^{12}$

Our cases had clinical diagnosis, as taking biopsy from uterus could not be considered right at that particular time in view of anticipated undesired bleeding complication.

We merely brought these two cases of the asymptomatic endometriosis in a primigravida and primipara, that occurred consecutively, one amidst dense adhesions as described in classical picture of endometriosis in repeat caesarean section and other not.

These cases are reported to bring attention to the readers to recommend injection depot- medroxy progesterone acetate in all these women to safe guard against chronic pelvic pain due to endometriosis in puerperium.

\section{Conclusion}

Clinically suspected endometriotic lesion must be biopsied and have CA-125 estimation for evidence based practice so as to cover post partum period with depot medroxy progesterone.

\section{Reference}

1. Sutthijumroon S, Tungphaisal S, Chandeying V. Endometriosis during pregnancy: Report of 3 cases. J Med Assoc Thai. 1989 May; 72(5):284-7.

2. Villa G, Mabrouk M, Guerrini M, Mignemi G, Colleoni GG, Venturoli S, Seracchioli R. Uterine rupture in a primigravida with adenomyosis recently subjected to laparoscopic resection of rectovaginal endometriosis: case report. J Minim Invasive Gynecol 2008 May-Jun; 15(3):360-1.

3. Ichikawa Y, Takano K, Higa S, Tanabe M, Wada A, Sugita M, Tsunoda H, Nishida M. Endometrial carcinoma coexisting with pregnancy, presumed to derive from adenomyosis: a case report. Int J Gynecol Cancer 2001 Nov-Dec; 11(6):488-90.

4. Passos F, Calhaz-Jorge C, Graça LM. Endometriosis is a possible risk factor for spontaneous hemoperitoneum in the third trimester of pregnancy. Fertil Steril 2008 Jan; 89(1):251-2.

5. O'Leary SM. Ectopic decidualization causing massive postpartum intraperitoneal hemorrhage. Obstet Gynecol 2006 Sep; 108(3 Pt 2):776-9.

6. Floberg J, Bäckdahl M, Silferswärd C, Thomassen PA. Postpartum perforation of the colon due to endometriosis. Acta Obstet Gynecol Scand 1984; 63(2):183-4.

7. Poder L, Coakley FV, Rabban JT, Goldstein RB, Aziz S, Chen LM. Decidualized endometrioma during pregnancy: recognizing an imaging mimic of ovarian malignancy. J Comput Assist Tomogr 2008 Jul-Aug; 32(4):555-8.

8. McCarthy-Keith DM, Coggins A. Perineal endometrioma occurring during pregnancy: a case report. J Reprod Med 2008 Jan; 53(1):57-8.

9. Patterson E, Herd AM. Incarceration of the uterus in pregnancy. Am J Emerg Med. 1997 Jan; 15(1):49-51.

10. Vercammen EE, D'Hooghe TM. Endometriosis and recurrent pregnancy loss. Semin Reprod Med 2000; 18(4):363-8.

11. Sangi-Haghpeykar H, Poindexter AN 3rd. Epidemiology of endometriosis among parous women. Obstet Gynecol 1995 Jun; 85(6):983-92.

12. Petrozza V, Magliocca FM, Pulvirenti S, Massimi G, de Salazar C, Carpino F. Asymptomatic peritoneal endometriosis following cesarean section. Minerva Ginecol 1993 Jul-Aug; 45(78):349-53. 